\title{
PENGARUH MANAJEMEN PROMOSI KESEHATAN DALAM MENINGKATKAN PENGETAHUAN KESEHATAN REPRODUKSI KADER POSYANDU DI DESA CIPANCUR, KECAMATAN KALIMANGGIS, KABUPATEN KUNINGAN
}

\author{
Ahmad Ropii ${ }^{1}$ \\ ${ }^{1}$ Sekolah Tinggi Ilmu Kesehatan Brebes, Jatibarang KM.8 Janegara, Brebes, Indonesia \\ Email: ahmadropii353@gmail.com
}

\begin{abstract}
Reproductive health is a health program that is currently receiving special attention, both globally and nationally. One of the causes of the high maternal mortality rate and infant mortality rate is the number of cases of early marriage. Immature reproductive organs in adolescent girls can be at risk for various diseases such as cervical cancer, breast cancer, myoma and uterine cancer. The number of cases of sexually transmitted diseases each year has increased significantly. The incidence of STIs in Indonesia tends to increase overall. "Gonorrhoea, Syphilis" was recorded in 2011 as many as 11,280. Of these cases, there were 5,131 (45.4\%) gonorrhea cases, 4725 (41.8\%) syphilis cases. In 2012 there were an increase of 13,043 cases distributed as many as $6003(46.0 \%)$ cases of gonorrhea, 5216 (40.0\%) cases of syphilis. This study aims to determine the effect of health promotion management in increasing knowledge of reproductive health of posyandu cadres in Cipancur Village, Kalimanggis District, Kuningan Regency.:This type of research is a quasi-experimental with a pre-test and post-test only design. The population is posyandu cadres of 20 people. The sampling technique used purposive sampling method in the posyandu cadre group in Cipancur Village. The instrument to measure in this study was a questionnaire that was given before and after counseling. Data analysis used paired t test with confidence $=0.05$. Based on the results of the analysis of the paired t test, it shows that there is an influence of health promotion management in increasing the knowledge of reproductive health of posyandu cadres with $p=0.000$. Based on these results, it can be concluded that there is an effect of health promotion management before and after reproductive health counseling on increasing knowledge on reproductive health of posyandu cadres. Researchers suggest that each cadre can convey knowledge to other communities so that other people can feel the results obtained by the cadres.
\end{abstract}

Keywords: Health Promotion Management, Reproductive Health, Health Cadre.

\begin{abstract}
ABSTRAK
Kesehatan reproduksi menjadi progam kesehatan yang saat ini mendapat perhatian khusus baik itu secara global ataupun nasional. Tinginya AKI dan AKB salah satunya diakibatkan oleh banyaknya kasus pernikahan dini. Belum matangnya organ reproduksi pada remaja perempuan dapat berisiko terhadap berbagai penyakit seperti kanker serviks, kanker payudara, mioma dan kanker rahim. Jumlah kasus penyakit menualar seksual tiap tahunnya mengalami peningkatan yang signifikan. Kejadian IMS di Indonesia cenderung meningkat secara keseluruhan. "Gonore, Sifilis" tercatat pada tahun 2011 sebanyak 11.280. Dari jumlah tersebut kasus ghonorrhea sebanyak $5.131(45,4 \%)$ kasus, sifilis sebanyak 4725 (41,8\%) kasus. Pada tahun 2012 meningkat sebanyak 13.043 kasus yang terdistribusi sebanyak 6003 (46,0\%) kasus gonorrhea, $5216(40,0 \%)$ kasus sifilis. Penelitian ini bertujuan untuk mengetahui pengaruh manajamen promosi kesehatan dalam meningkatkan pengetahuan kesehatan
\end{abstract}


reproduksi kader posyandu di Desa Cipancur Kecamatan Kalimanggis Kabupaten Kuningan. Jenis penelitian adalah eksperimen semu dengan pre-test dan post-test only design. Populasi adalah kader posyandu sejumlah 20 orang. Teknik pengambilan sampel menggunakan metode purposive sampling pada kelompok kader posyandu yang berada di Desa Cipancur. Instrumen untuk mengukur dalam penelitian ini adalah kuesioner yang di berikan sebelum dan setelah penyuluhan. Analisis data menggunakan uji paired t test dengan kepercayaan $\alpha=0,05$. Berdasarkan hasil analisis uji paired t test menunjukkan bahwa terdapat pengaruh manajemen promosi kesehatan dalam meningkatkan pengetahuan kesehatan reproduksi kader posyandu dengan nilai $\mathrm{p}=0,000$. Berdasarkan hasil tersebut dapat disimpulkan ada pengaruh manajemen promosi kesehatan sebelum dan setelah penyuluhan kesehatan reproduksi terhadap peningkatan pengetahuan kesehatan reproduksi kader posyandu. Peneliti menyarankan agar setiap kader bisa menyampaikan pengetahuan ke masyarakat lainya agar masyarakat lainya dapat merasakan hasil yang didapatkan oleh kader.

Kata Kunci: Manajemen Promosi Kesehatan, Kesehatan Reproduksi, Kader Kesehatan.

\section{INTRODUCTION}

Kesehatan reproduksi menjadi progam kesehatan yang saat ini mendapat perhatian khusus baik itu secara global ataupun nasional. Saat ini, kesehatan reproduksi di Indonesia yang diprioritaskan baru mencakup empat komponen/program, yaitu Kesehatan Ibu dan Bayi Baru Lahir, Keluarga Berencana, Kesehatan Reproduksi Remaja, serta Pencegahan dan Penanggulangan Penyakit Menular Seksual (PMS) termasuk HIV/AIDS. Angka Kematian Ibu (AKI) dan Angka Kematian Bayi (AKB), kejadian IMS (Infeksi Menular Seksual) yang meningkat cukup pesat tiap tahunnya manjadi permasalahan utama kesehatan reproduksi. Tingginya kasus kekerasan seksual pada anak dan perempuan, serta kasus-kasus penyimpangan seksual juga semakin mengkhawatirkan.

Tinginya AKI dan AKB salah satunya diakibatkan oleh banyaknya kasus pernikahan dini. Belum matangnya organ reproduksi pada remaja perempuan dapat berisiko terhadap berbagai penyakit seperti kanker serviks, kanker payudara, mioma dan kanker rahim (Sangaji, 2017). Jumlah kasus penyakit menualar seksual tiap tahunnya mengalami peningkatan yang signifikan. Kejadian IMS di Indonesia cenderung meningkat secara keseluruhan. "Gonore, Sifilis" tercatat pada tahun 2011 sebanyak 11.280. Dari jumlah tersebut kasus ghonorrhea sebanyak $5.131(45,4 \%)$ kasus, sifilis sebanyak 4725 (41,8\%) kasus. Pada tahun 2012 meningkat sebanyak 13.043 kasus yang terdistribusi sebanyak $6003(46,0 \%)$ kasus gonorrhea, 5216 (40,0\%) kasus sifilis (Nilasari, 2014).

Angka Kematian Ibu (AKI) atau Maternal Mortality Rate (MMR) tidak tersedia datanya. Sebagai gambaran berdasarkan hasil survey yang dilaksanakan Badan Pusat Statistik Provinsi Jawa Barat tahun 2020 dalam Profil Dinas Kesehatan Jawa Barat memperhitungkan AKI Provinsi Jawa Barat sebesar 321,15 per 100.000 kelahiran hidup. Jumlah Kematian Ibu atau jumlah kelahiran hidup di Kabupaten Kuningan menunjukkan data yang berfluktuasi, tahun 2018 ke tahun 2020 ada penurunan kasus tetapi meningkat kembali di tahun 2021. Berdasarkan hasil pelacakan dan Audit Maternal Perinatal ternyata kematian maternal pada tahun 2021 disebabkan karena komplikasi yaitu perdarahan (6 kasus), hypertensi dalam kehamilan (4 Kasus) dan penyebab lain (9 kasus).

Perempuan dan anak-anak menjadi kelompok yang sangat rentan terhadap kekerasan seksual karena selalu diposisikan sebagai sosok lemah. Kekerasan seksual terhadap perempuan dan anak dapat terjadi kapan saja dan di mana saja. Siapa pun bisa menjadi pelaku kekerasancseksual terhadap 
perempuan dan anak. Kasus kekerasan seksual pada perempuan dan anak di tengah pandemi juga kian mengkhawatirkan. (Noviana, 2015). Menurut Komnas Perempuan, pada tahun 2018 jumlah kasus kekerasan seksual pada perempuan mencapai 5.280 kasus Sedangkan menurut KPAI, total kasus kekerasan seksual pada anak pada tahun 2019 dilaporkan sebanyak 350 kasus. Jumlah ini meningkat 70 persen dibandingkan tahun sebelumnya (Komnas Perempuan, 2020).

Era pandemi Covid-19 memengaruhi banyak sektor. Salah satunya adalah sektor kesehatan yang menjadi sektor paling terdampak selain sektor ekonomi. Tingginya jumlah kasus infeksi Covid19 dan jumlah orang yang meninggal akibat Covid-19 menjadi salah satu bukti yang dapat diketahui bersama. Selain hal itu, progam-progam kesehatan yang lain juga terdampak secara langsung maupun tidak langsung. Salah satunya yaitu progam kesehatan masyarakat yang umumnya banyak melibatkan massa seperti pada kegiatan penyuluhan dan pendidikan kesehatan. Hal ini menjadi masalah serius karena dikhawatirkan banyak progam kesehatan masyarakat menjadi mandeg disebabkan adanya pembatasan terhadap kegiatan yang menimbulkan kerumunan orang. Pada kelompok tertentu seperti ibu-ibu masih banyak yang kurang terpapar informasi kesehatan dengan baik dan benar. Banyaknya Hoax yang beredar melalui media sosial maupun aplikasi berkirim pesan juga mengakibatkan disinformasi dikalangan masyarakat.

Posyandu merupakan salah satu bentuk Upaya Kesehatan Bersumber Daya Masyarakat (UKBM) yang dikelola dan diselenggarakan dari, oleh, untuk dan bersama masyarakat. Setiap posyandu biasanya terdapat beberapa orang yang menjadi kader yang mempunyai tugas dan fungsi. Kader Posyandu merupakan anggota masyarakat yang dipilih dari dan oleh masyarakat, mau dan mampu bekerja bersama dalam berbagai kegiatan kemasyarakatan secara sukarela. Salah satu fungsi dari kader posyandu adalah upaya kesehatan dengan membagikan informasi terkait kesehatan pada masyarakat terutama pada ibu-ibu di sekitar lingkungan rumahnya (Kemenkes RI, 2011). Penelitian ini bertujuan untuk mengetahui pengaruh manajamen promosi kesehatan dalam meningkatkan pengetahuan kesehatan reproduksi kader posyandu di Desa Cipancur Kecamatan Kalimanggis Kabupaten Kuningan.

\section{METHOD}

Jenis penelitian adalah eksperimen semu dengan pre-test dan post-test only design yaitu penelitian eksperimen yang dilaksanakan pada satu kelompok saja yang dipilih secara random dan tidak dilakukan tes kestabilan dan kejelasan keadaan kelompok sebelum diberi perlakuan. Populasi adalah kader posyandu sejumlah 20 orang. Teknik pengambilan sampel menggunakan metode purposive sampling pada kelompok kader posyandu yang berada di Desa Cipancur. Metode purposive sampling merupakan teknik pengambilan sampel sumber data dengan pertimbangan tertentu. Instrumen untuk mengukur dalam penelitian ini adalah kuesioner yang di berikan sebelum dan setelah penyuluhan. Analisis data menggunakan uji paired t test dengan kepercayaan $\alpha=0,05$.

Penelitian ini dilakukan dengan cara memberikan pre test dan post test soal tentang kesehatan reproduksi kepada 20 responden. Ketika intervensi dilakukan bukan dibantu juga dengan media promosi 
kesehatan lainya seperti: leaflet, poster dan lain sebagainya. Waktu penelitian selama 1 hari pada tanggal 20 Agustus 2021.

\section{RESULTS AND DISCUSSION}

\section{Results}

Hasil Uji paired T Test dapat dijelaskan dalam tabel dibawah ini:

Tabel 1. Hasil Uji paired T Test manajemen promosi kesehatan dengan pengetahuan

\begin{tabular}{|l|l|l|l|l|l|}
\hline \multirow{2}{*}{ Variabel } & \multicolumn{2}{|l|}{$\begin{array}{l}\text { Sebelum } \\
\text { intervensi }\end{array}$} & \multicolumn{2}{l|}{ Setelah intevensi } & \multirow{2}{*}{ pvalue } \\
\cline { 2 - 6 } & Mean & SD & Mean & SD & \\
\hline $\begin{array}{l}\text { Pengetahuan } \\
\text { Kesehatan } \\
\text { Reproduksi }\end{array}$ & 60,95 & 2,282 & 86,20 & 3,548 & 0,000 \\
\hline
\end{tabular}

Berdasarkan Tabel 5.2 menunjukkan bahwa dari hasil uji statistik $\mathrm{t}$ dependent diperoleh $p$ value $=0,000$ dimana hasil tersebut lebih kecil dari nilai alpha $(p<0.05)$, artinya terdapat pengaruh manajemen promosi kesehatan dalam meningkatkan pengetahuan kesehatan reproduksi kader posyandu di Desa Cipancur Kecamatan Kalimanggis Kabupaten Kuningan dengan nilai p=0,000. Dapat dijelaskan juga terdapat peningkatan pengetahuan dari yang sebelumnya rata-rata nilai 60,95 dan meningkat menjadi 86,20 antara sebelum dan sesudah dilakukan perlakuan.

\section{Discussion}

Berdasarkan hasil penelitian ini menunjukkan terdapat pengaruh manajemen promosi kesehatan dalam meningkatkan pengetahuan kesehatan reproduksi kader posyandu di Desa Cipancur Kecamatan Kalimanggis Kabupaten Kuningan dengan nilai $p=0,000$. Penelitian ini sejalan dengan Harun (2018) yang menyatakan terdapat pengaruh promosi kesehatan untuk meningkatkan pengetahuan pada kader yang ada anggota masyarakatnya mengalami gangguan jiwa di Kabupaten Sukoharjo. Sejalan dengan penelitian anggaraeni (2015) yang menyatakan ada pengaruh pendidikan kesehatan reproduksi dengan media VLM (Video Learning Multimedia) terhadap pengetahuan dan sikap kader kesehatan dengan nilai $\mathrm{P}=0,000$. Kesehatan reproduksi menurut $\mathrm{WHO}$ adalah kesejahteraan fisik, mental dan sosial yang utuh bukan hanya bebas dari penyakit atau kecatatan, dalam segala aspek yang berhubungan dengan sistem reproduksi, fungsi serta prosesnya (Kusmiran, 2011).

Meluasnya liputan media massa sampai ke pelosok negeri yang menyajikan fakta tentang kesehatan reproduksi, baik positif maupun negatif mendorong pemerintah, perorangan, swasta dan lembaga swadaya masyarakat untuk mengambil peran aktif dalam mensosialisasikan sekaligus memberikan jalan keluar atas permasalahan kesehatan reproduksi (Imamah, 2009). Peneliti melihat 
betapa pentingnya sosialisasi sejak dini tentang kesehatan reproduksi dan jika lalai salah satu dampaknya angka kehamilan di usia dini dan angka penularan penyakit IMS (Infeksi Menular Seksual) meningkat.

Dalam penelitian ini promosi kesehatan tidak dilakukan hanya dengan penyuluhan namun adanya pemilihan media pendidikan kesehatan ditentukan oleh banyaknya sasaran, keadaan geografis, karakteristik partisipan, dan sumber daya pendukung. Misalnya di daerah terpencil yang hanya dapat dicapai dengan pesawat terbang khusus dan pendidikan kesehatan yang diinginkan adalah yang mencapai sebanyak mungkin sasaran, maka media yang dipilih adalah flyer atau media elektronik jika sumber dayanya memungkinkan. Munir (2013) menyatakkan beberapa media pendidikan kesehatan dapat juga dipergunakan sebagai alat peraga jika pendidik kesehatan bertemu langsung dengan partisipan dalam proses pendidikan kesehatan.

Dengan diadakannya pendidikan kesehatan yang berisi tentang materi kesehatan reproduksi diharapkan pengetahuan dan sikap dari kader kesehatan tersebut dapat meningkat, karena apabila informasi yang diterima sedikit akan mempengaruhi pengetahuan dan sikap para kader, dan akan timbul masalah-masalah kesehatan reproduksi di kalangan masyarakat. Diharapkan dengan metode pendidikan kesehatan baik dengan penyuluhan langsung atau media pembelajaran lainya ini para kader dapat dengan mudah menyerap materi yang disajikan.

\section{CONCLUSION}

Berdasarkan hasil tersebut dapat disimpulkan terdapat pengaruh manajemen promosi kesehatan sebelum dan setelah penyuluhan kesehatan reproduksi terhadap peningkatan pengetahuan kesehatan reproduksi kader posyandu sehingga peneliti menyarankan agar setiap kader bisa menyampaikan pengetahuan ke masyarakat lainya agar masyarakat lainya dapat merasakan hasil yang didapatkan oleh kader dalam kegiatan penelitian yang diikutinya

\section{ACKNOWLEDGMENTS}

Ucapan terima kasih kami berikan kepada Posyandu di Desa Cipancur, Kecamatan Kalimanggis, Kabupaten Kuningan yang telah menjadi lokasi penelitian.

\section{REFERENCES}

Anggraeni, V.D. (2015). Laporan Umum Praktik Kerja Lapangan PT. Indo Acidatama Tbk, Kemiri,

Kebakkramat, Karanganyar. Yogyakarta: Jurusan Kesehatan Lingkungan Politeknik Kesehatan.

Dinas Kesehatan Jawa Barat (2020). Riset Kesehatan Dasar Provinsi Jawa Barat

Imamah. 2009. Tingkat Pengetahuan Remaja Tentang Kesehatan Reproduksi. Vol $1: 2$.

Kementerian Kesehatan RI. (2020) Kesehatan Reproduksi. Jakarta: Pusat Data dan Informasi Kementerian Kesehatan RI

Komnas Perempuan RI. (2020) Kesehatan Reproduksi Pada Remaja wanita. 
Kusmiran, E (2011). Kesehatan reproduksi remaja dan wanita. Jakarta: Salemba Medika

Munir, M. 2013. Survei BKKBN_Tiap Tahun Remaja Seks Pranikah Meningkat. (Diakses tanggal 02 Agustus 2021).

Nilasari E. (2013) Hubungan antara lingkar pinggang dan Rasio Lingkar Pinggang Panggul dengan Tekanan Darah pada Wanita Dewasa. Jurnal Unimus.

Noviana, Ivo. 2015. Kekerasan Seksual Terhadap Anak: Dampak dan Penanganannya, sosio Informa, 01 (01) Januari-April 2015. Puslitbang Kesos, Kemensos RI.

Purnomo. (2018). Promosi Kesehatan Untuk Mengetahui Perubahan Pengetahuan, Sikap, Dan Kecenderungan Berperilaku Pada Kader Yang Ada Anggota Masyarakatnya Yang Mengalami Gangguan Jiwa Di Kabupaten Sukoharjo. 1(2), 80-84.

Sangaji. (2020). Implementasi Kebijakan Program Pelayanan Kesehatan Dalam Rangka

Menurunkan Aki Dan Akb Di Puskesmas Sukaraja Kabupaten Sukabumi (Studi Empiris Pada Puskesmas Sukaraja Kabupaten Sukabumi). Jurnal MODERAT, 6(4), 868-891. https://jurnal.unigal.ac.id/index.php/moderat/article/view/3609. 